\title{
Geoduck Clam (Panopea Abrupta) Demographics and Mortality Rates in the Presence of Sea Otters (Enhydra Lutris) and Commercial Harvesting
}

\author{
Rhonda D. Reidy ${ }^{*}$ and Sean P. Cox
}

School of Resource and Environmental Management, Simon Fraser University, Burnaby, British Columbia V5A 1S6, Canada

\begin{abstract}
In British Columbia, expanding sea otter (Enhydra lutris) populations are creating concerns among commercial harvesters about the potential predation impacts on exploitable geoduck clam (Panopea abrupta) stocks. We analysed fishery-independent surveys of exploited geoduck clam populations along a gradient of sea otter occupancy on the west coast of Vancouver Island, British Columbia, Canada to assess relationships between otter presence, commercial fishery removals of geoduck, and geoduck population demographics. Geoduck mean density, age composition, and estimated total mortality were influenced by a combination of variables, and therefore, we could not differentiate among geoduck populations according to sea otter presence or absence alone. As expected, we found a strong association between commercial fishery removals and geoduck clam total mortality rates. In contrast, the local numbers of sea otters were not an important factor affecting geoduck total mortality. A more balanced study design and greater sampling intensity would increase the power to detect whether sea otter predation affects harvestable geoduck stocks. Also, knowledge of the consumption rate by sea otters of geoduck throughout the year, in combination with survey data of unfished geoduck populations, would facilitate better prediction of how geoduck clam mortality rates might change as sea otters re-colonise new areas.
\end{abstract}

Keywords: British Columbia, commercial fisheries, geoduck clam, predation mortality, sea otter, Vancouver Island.

\section{INTRODUCTION}

One of the main objectives of fisheries management is to ensure sustainable yield from fish stocks over time [1]. A relatively new concern for management is emerging in regions where commercial fisheries co-occur with marine mammal populations that are recovering from historical over-harvesting [2]. Increases in natural predator numbers may be influencing prey populations in ways that concern conventional fisheries stock assessment and management [2, 3]. Along the west coast of Vancouver Island (WCVI), British Columbia, Canada, for example, sea otters (Enhydra lutris) were successfully reintroduced in the 1970s, and their expanding populations may now conflict with the management of high-value invertebrate fisheries that developed in their absence [4].

Prior to commercial exploitation in the $18^{\text {th }}$ and $19^{\text {th }}$ centuries, sea otters almost certainly limited the quantity and distribution of their near-shore invertebrate prey [5-7]. Ecologists speculate that under reduced predation pressure by otters, many invertebrate species increased in average size and abundance [8], which may have enabled the development of major new commercial shellfish fisheries in the sea otter's former range $[9,10]$. Following their reintroduction to the WCVI, sea otters were presumably inconsequential due to their low population numbers near fishing areas. This situation is changing, and fisheries managers are requesting

\footnotetext{
*Address correspondence to this author at 2768 Satellite Street, Victoria, British Columbia V8S 5G8, Canada; Tel: 250-598-8469;

E-mail: rreidy@gmail.com
}

that scientists adopt a multi-species approach to stock assessments where sea otters and shellfish fisheries overlap [e.g., 11, 12].

Despite considerable scientific research on the trophic ecology of sea otters [8], we currently know little about how sea otters directly or indirectly affect invertebrate fisheries $[4,9]$. Insufficient information has been available due to a lack of quantitative studies aimed at assigning the causes of shellfish mortality to different sources, including sea otter predation and fisheries [9]. In this paper, we evaluate the potential effects of sea otter predation on a WCVI fishery for the geoduck clam (Panopea abrupta). Reviews of the known (and expected) effects of sea otters on commercially important invertebrate species in British Columbia can be found in Watson and Smith [4].

Geoducks are distinct from the typical commercially fished species of sedentary invertebrates in British Columbia such as urchins, sea cucumbers, and other bivalves. They are the largest burrowing clams in the world and may weigh up to $4.5 \mathrm{~kg}$ at $20 \mathrm{~cm}$ shell length [13] and are also among the longest-lived animals known, with a maximum-recorded age of 168 years [14]. They can burrow to a depth of $1 \mathrm{~m}$ in unconsolidated substrates, but tend to aggregate in large numbers in beds up to $0.5 \mathrm{~km}^{2}$ in mud-sand or sand $[15,16]$, and at depths ranging from inter-tidal to over $100 \mathrm{~m} \mathrm{[16].} \mathrm{In} \mathrm{the} \mathrm{shal-}$ lower beds, where fisheries operate, geoducks reach sexual maturity at around 3 years and a marketable size of approximately $1 \mathrm{~kg}$ between 6 and 12 years [14]. Geoduck populations in British Columbia cover approximately $264 \mathrm{~km}^{2}$ of coast [17] and support a profitable dive fishery [18]. Between 
2005 and 2009, the average annual landed value was CDN\$ 32 million, with approximately $11 \%$ harvested from the WCVI ${ }^{\mathrm{i}}$. Although fishing was initially concentrated in the subtidal waters along the east coast of Vancouver Island, market expansion resulted in a relatively fast spread of fishery exploitation to the west coast of Vancouver Island by 1979, and to the north coast of mainland British Columbia by 1980, where new beds continue to be discovered $[17,19]$.

Geoduck populations are potentially linked through the drifting and inter-mixing of larvae [18], although some populations (e.g., deep-water stocks) may be spatially separate from the fishable populations that contribute to regionalscale recruitment processes ${ }^{\mathrm{ii}}$. Mortality of geoduck clams is high during larval and juvenile stages [20], but decreases considerably after four to five years when geoducks reach their maximum refuge depth [20]. While the estimated average natural mortality rate $(M)$ for geoduck populations varies between 0.014 and $0.054 \mathrm{yr}^{-1}$ [16], Zhang and Campbell [21] estimated $M$ to be $0.036 \mathrm{yr}^{-1}$ (SE $0.003 \mathrm{yr}^{-1}$ ) for the WCVI region. Zhang and Hand [18] later suggested that adult mortality may be higher in regions in the WCVI where sea otters are established.

Commercial harvests and SCUBA surveys target geoduck stocks from $3 \mathrm{~m}$ to the maximum commercial diving depth of $20 \mathrm{~m}[14,15]$. Although little is known about geoduck populations at greater depths, or in harder substrates, these populations are probably unexploited by both fisheries [14, 15] and sea otters. The Under Water Harvesters' Association (UHA) and the Canadian Department of Fisheries and Oceans (DFO) co-manage British Columbia's geoduck fishery on a bed-by-bed basis [12]. The long-term management goal is to maintain a bed's mean fishable biomass at above $50 \%$ of the estimated unfished level over a 50 year period [22]. Both the UHA and DFO are concerned that recent declines in estimated geoduck stocks in this area are due to a combination of intense commercial harvesting and increased sea otter predation [12, 22].

Optimal habitats for sea otters are relatively shallow $(<40$ $\mathrm{m})$ and near-shore $(<1-2 \mathrm{~km})$ [23] and overlap with geoduck fishery areas. Sea otters forage by diving to the sea floor, capturing prey with their forelimbs, and consuming these prey items at the surface [8]. Sea otters forage extensively on invertebrates [8], and adult male sea otters weighing up to 46 $\mathrm{kg}$ [8] can consume more than $20 \%$ of their body weight per day [23]. While at sea, otters rest in large aggregations of up to 100 or more animals that can remain in the same general area from months to years [24]. Sea otter population size is controlled largely through density-dependent responses to food limitation [25]; however, communities of clam species in soft-bottomed habitats are currently abundant in British Columbia [4]. Sea otters are recognized as a "keystone species" because they contribute to the community structure of both rocky and soft-bottomed habitats by reducing the size and abundance of grazing invertebrates, particularly sea urchins (Strongylocentrotus spp.) [8]. Sea otters are listed as

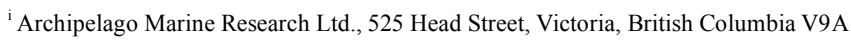
5S1, Canada, unpublished data, 2009.

ii C. Hand, Fisheries and Oceans Canada, Pacific Biological Station, 3190 Hammond Bay Road, Nanaimo, British Columbia V9R 5K6, Canada, personal communication, 2009. being of Special Concern under Canada's Species at Risk Act [26] and as a Threatened Species under the British Columbia Wildlife Act [27]. The Marine Mammal Regulations of Canada's Fisheries Act also directly protects sea otters by making it an offence to kill, harm, or harass any marine mammal.

The literature generally indicates that the recovery of sea otters can be associated with losses of productive shellfish fisheries [e.g., 4, 10, 28]. Potential interactions between sea otters and geoduck fisheries have not been investigated quantitatively in British Columbia. While previous studies have not detected an effect of sea otter predation on the deeply burrowing geoducks in California [29] or in Alaska [7], predation on geoducks may possibly increase with a decline in abundance of the sea otter's preferred prey of sea urchins and other species of shallow-buried clams [7]. Geoduck harvesters in British Columbia believe that sea otters are digging for geoducks and that substantial loss in economic yield should be expected in areas with recolonizing sea otters. However, the intensity of competition between sea otters and geoduck harvesters is particularly difficult to evaluate, due to the complex ecology of the geoduck populations and highly variable recruitment occurring over years to decades [16]. Here, we develop an analytical framework to help managers identify relevant information gaps within present geoduck fishery and sea otter data. Our objective was to quantitatively assess whether sea otter predation impacts are of sufficient magnitude to threaten the viability of commercial geoduck clam fisheries in British Columbia by (1) estimating geoduck total mortality rates across a gradient of sea otter abundance, and (2) partitioning these total mortality rates into estimated fishery and sea otter components, assuming that these components are additive. Fishery-independent geoduck survey data from the WCVI and catch curve analyses are used to explore these relationships and other fundamental life history parameters of geoduck clams.

\section{MATERIALS AND METHODS}

We used data collected between 1996 and 2008 by Fisheries and Oceans Canada, the Underwater Harvesters' Association, and occasionally First Nations (Kwakiutl Territorial Fisheries Commission and Haida fisheries divers). Details of annual geoduck clam surveys can be found in Bureau et al. [14]. The geoduck database consists of approximately 103 fishery-independent surveys of the exploited geoduck beds in British Columbia [12], which comprise approximately $57 \%$ of the total estimated habitat area for geoduck ${ }^{\text {iii }}$. The primary goal of these surveys is to establish geoduck population parameters over time (i.e., natural recruitment and growth rates), as well as to study the long-term effects of harvesting on the fishable wild stocks [12]. Of these surveys, $22(25 \%)$ were along the WCVI and provide specific fisheryindependent biological information on geoduck abundance, distribution, and age composition used in this study.

\section{STUDY SITES AND GEODUCK SURVEY DATA}

Our study region extends approximately $250 \mathrm{~km}$ from the northwest end of Vancouver Island in Quatisno Sound to the

\footnotetext{
iii G. Dovey, West Coast Geoduck Corp., PO Box 781, Ladysmith, British Columbia V9G 1A6, Canada, personal communication, 2008.
} 


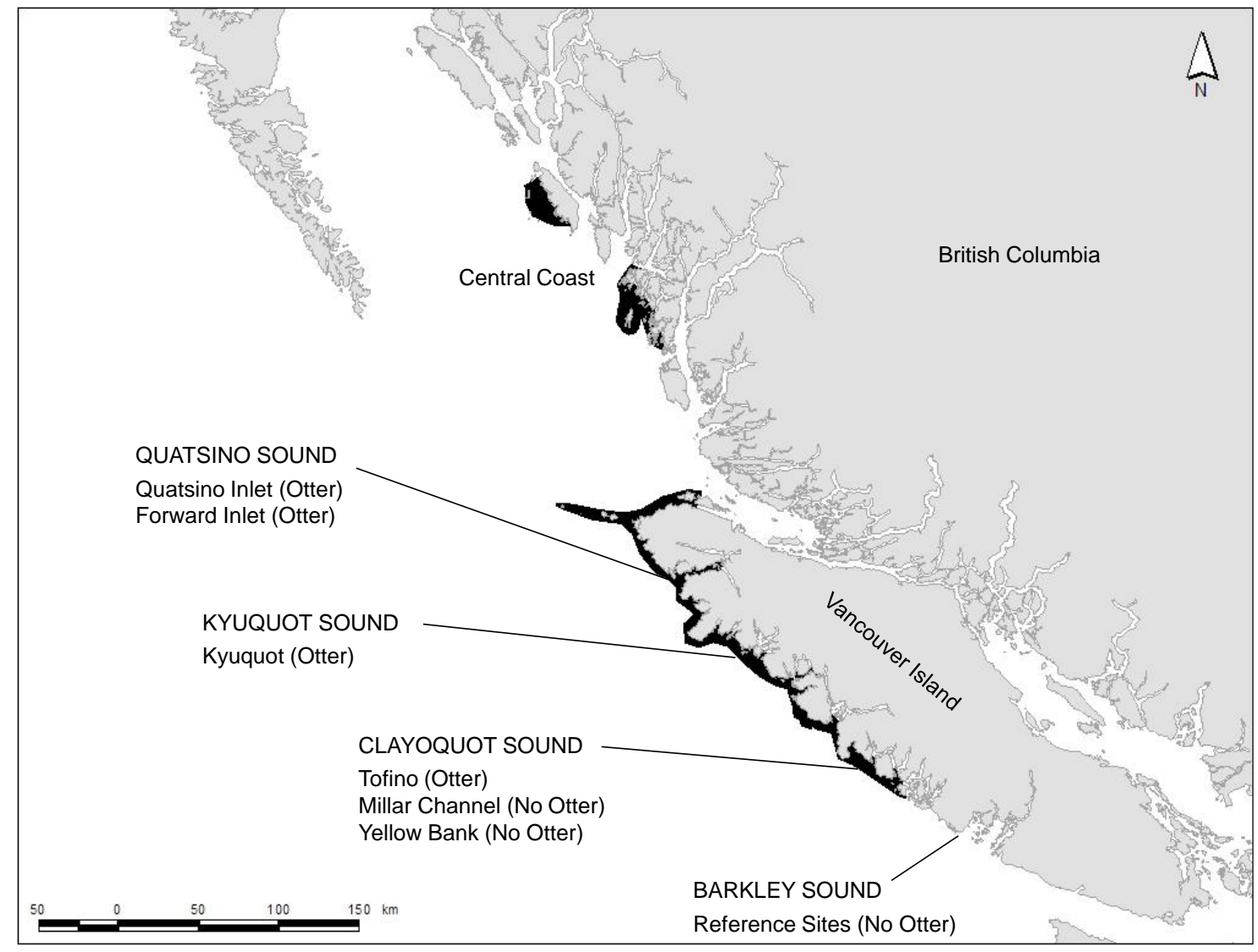

Fig. (1). Distribution of sea otters in British Columbia. Dark areas represent the total occupied range as of 2009 along the WCVI and the Central Coast. Although close to the otter site near Tofino, Millar Channel and Yellow Bank are areas where large aggregations of sea otters are not yet present. Barkley Sound is outside the sea otters' current range. Modified from Nichol et al. [31].

southeast in Barkley Sound (Fig. 1). The region includes the site near Kyuquot Sound where sea otters were reintroduced in the early 1970 s, as well as where otters have recently (i.e., 2004) expanded their range in Clayoquot Sound near Tofino. Some areas in Clayoquot Sound, and all areas in Barkley Sound, are presently outside the foraging range of the large aggregations of sea otters. Geoduck clam beds within the study region are located nearshore in relatively high-wave energy, islet and rocky reef environments less than $40 \mathrm{~m}$ deep, and have similar oceanographic conditions (e.g., water temperature, salinity, and water density) and physical structure (e.g., bathymetry) [30].

We define a "study site" as a specific geoduck clam bed, or portion thereof, within a larger fishing area. In collaboration with the UHA and DFO, we selected study sites based on the following requirements: $(i)$ a relatively long timeseries of commercial geoduck fishing from the beginning of fishing in the 1980s, (ii) a similarity of biophysical conditions, (iii) the presence and absence of sea otters, and (iv) the availability of two years of fishery-independent survey data for the same geoduck beds. Study sites classified "without otters" are those where no otters or very few sea otters have been observed by commercial harvesters; evidence is rare or non-existent of sea otter foraging (e.g., no empty geoduck shells lying on the surface or otter holes in the substrate); and commercial fishing for geoduck clams has occurred over a long period. Sites classified as "otters" are those where an abundance of sea otters have been reported in the area by commercial fishers or observed during otter surveys, and where evidence of otter foraging is generally common. This selection process resulted in 11 study sites within 3 commercially fished regions on the WCVI; however, the number of "without otters" sites were minimal. We thus included sites from a fourth region in Barkley Sound where sea otters are not yet established. Although no bed-specific, repeated survey sites were available in Barkley Sound, we included these "without otters" sites for three reasons. First, they were the only other surveyed sites on the WCVI that are still being fished today, and that are in a similar habitat to study sites in Quatsino, Kyuquot, and Clayoquot Sounds. Second, they have both survey estimates of density and age composition for the same geoduck beds. Third, three of the sites were surveyed in 2002 and the others were surveyed in 2005 and provide a useable time frame for the analysis. The final selection resulted in 17 study sites in 4 commercially fished regions on the WCVI in which sea otters were present or absent. The sites ultimately provided 16 survey years in otter areas in Quatsino, Kyuquot and Clayoquot Sounds, and 12 survey years in the areas without otters in Clayoquot and Barkley Sounds. 
Surveys took place over one or two weeks in each survey year. DFO followed a stratified random design, where geoduck beds were the strata, and transect locations were drawn randomly from within them on charts a priori [14]. Survey divers worked in pairs at one meter on either side of a transect, stopping every few meters to conduct a complete census of $10 \mathrm{~m}^{2}$ secondary sampling units (quadrats). Eleven sites comprised repeat survey data, while the six supplementary sites in Barkley Sound each had a single survey year of data. Divers collected a biological sample on the last day of a survey, using standard commercial fishing gear to harvest geoducks from the substrate [14]. Only seven of the sites have geoduck age-composition data from two different survey years for statistical comparison. Geoduck agecomposition sample sizes ranged from 141 to 562 geoducks. A "sample" was comprised of one or more sub-samples taken from a single study site, within a larger commercially fished area. Some study sites comprised only a portion of a geoduck bed that had been surveyed twice, with a single subsample of fewer than 200 clams collected from that portion of the bed in each survey year. We assumed every sample was representative of the age composition of the geoduck population of the study site from which it was taken.

There were no data on the catch per unit of effort from the fishery in the study sites and the fishing effort has varied across fishing regions [14]. We used cumulative site-specific landings from the beginning of fishing in the 1980s, up to the first and second survey years at each site to represent the effects of fishing on geoduck mortality. Total fishery landings from a study site area (millions of pounds) were strongly related to total diver fishing hours $\left(r^{2}=0.99\right.$, $F_{1,11}=966.9, P<10^{-5}$ ), indicating that fishery removals are an adequate index of fishing effort. We therefore used fishery landings in place of fishing effort in our analyses. Note that landings were summarized to the geoduck bed level and were the most detailed level of data available. Therefore, landings in our analysis correspond to a larger area of fishing within which a study site is located. In areas where no fishing occurred in the year of a geoduck survey, we summed the total landings up to the most recent fishing year, prior to the year of a survey. Converting fishery landings to a density in order to better scale the effect of removals to initial geoduck density was not possible because of a mismatch of spatial scales. We obtained data for site-specific landings from the general area that contained survey transects but not from the transect area specifically (i.e., a "study site").

\section{SEA OTTER SURVEY DATA}

Information about sea otter abundance in British Columbia is collected by small vessel surveys during summer months [31]. Because our geoduck study sites are very small $\left(\right.$ all $<8,000 \mathrm{~m}^{2}$ ) relative to the foraging range of sea otters, we used the nearest sea otter abundance estimates from Nichol et al. [31] to represent the number of otters in the geographic region of each study site around the time of the geoduck surveys. In our analysis, the Kyuquot region corresponded to three sea otter survey segments in Nichol et al. [31]. We summed the counts from all three segments in the year of a geoduck survey to obtain a single abundance estimate for the region. In addition, no abundance estimates were available in Nichol et al. [31] in the first geoduck sur- vey year for the Kyuquot and Quatsino regions in 1998 and 1996, respectively. For those sites, we used the most recent sea otter abundance estimates prior to the geoduck survey year.

\section{DATA ANALYSIS}

For each study site, we calculated the mean density of geoduck clams in a survey year as the total number of geoduck siphons recorded by survey divers along a transect divided by the total area sampled over all transects. We used a non-parametric bootstrap percentile to obtain a $95 \%$ confidence interval for the mean geoduck density for each survey year. For study sites with repeated samples, we used a Welch Two-Sample $t$-test of the null hypothesis of no difference in the mean geoduck density in each site between the two survey years, using the standard Type I error rate of 0.05 . The lack of adequate transect data for the first survey year at one site resulted in its exclusion from the statistical comparison. We also statistically compared geoduck mean age between sample years for the sites with paired samples. We used the Welch Two-Sample $t$-test of the null hypothesis of no difference in the mean age of geoducks between the two survey years. Most of the age data did not meet the assumptions of equal variances and normality; however, the Welch $t$-test is robust to violations of these assumptions at large sample sizes [32].

A graphical plot of the age-frequency distribution of a sample of catch (i.e., a catch curve) typically describes an ascending left limb, a domed middle segment, and a descending right limb. Hilborn and Walters [1] ascribe this pattern to an increasing vulnerability to the fishing gear (ascending limb), which peaks as the younger individuals become "fully recruited" to the fishery, and to natural mortality and harvesting (descending limb), which effectively reduces the number of older individuals in the population over time. Therefore, the age composition of an exploited species is an indicator of the effect of harvesting that can be used to provide information about the total mortality rate on the stock [1]. We applied Chapman and Robson's [33] method to estimate the total mortality rate, $Z$, from age frequency data for each study site and survey year. The Chapman-Robson method has been shown to have generally good estimation properties compared to alternative estimators [34], and is based on a minimum variance, unbiased estimator for the survival parameter $S=\mathrm{e}^{-Z}[33,34]$. The fairly strong assumptions (i.e., unlikely to be true) behind this method include annual recruitment that is constant amid continuous natural and fishing mortality for all sites, and no stochastic variation in $Z$ over time. This method also assumes that some reference age exists above which vulnerability to fishing is constant [35]. We recoded geoduck ages so that age-11 served as the reference age- 0 in the model to cover the range of assumed recruitment ages of 8-10 years in Orensanz et al. [16]. The estimator of the total mortality rate $Z$ is

$$
\begin{aligned}
& \hat{Z}=\log (1+\bar{X}-1 / n) / \bar{X} \\
& \hat{\sigma}^{2}=\frac{\left(1-e^{-Z}\right)^{2}}{n e^{-Z}}
\end{aligned}
$$


where $\bar{X}$ is the mean recoded age of the sample, $n$ is the sample size and $\sigma^{2}$ is the variance of $Z$ [34]. The standard error of $Z$ was calculated as the square root of the variance. We tested the performance of this estimator because the agecomposition sample sizes appeared small relative to the number of age classes in the geoduck sample populations. We simulated 1,000 estimates of $Z$ by sampling from an exponentially distributed age-frequency [34] with a known total mortality rate and sample sizes derived from the observed data. Percent bias was computed relative to the original Chapman-Robson estimate.

We used a linear mixed effects model to test whether sea otters are an important factor affecting geoduck total mortality rate among study sites. Mixed-effects modeling is appropriate when the outcome values are measured repeatedly within the same units and have correlated error [36]. In our full model, the outcome variable geoduck mortality is contributed to by the additive fixed effects of the number of otters in the region of a study site and fishery landings, as well as the random effect of the geographic area a study site is located within, which is also the area from which the landings were taken. We assumed that the first and second survey year is implicitly nested within the random effect of the study site location. We checked for normality and homogeneity by visual inspection of a plot of residuals against fitted values. To assess the validity of the mixed effects analysis, we performed a likelihood ratio test comparing the model with fixed effects to the null model with only the intercept and random effect. We used Akaike information criterion (AIC) to identify the best model, as recommended by Burnham and Anderson [37]. We considered all possible models independently and report the AIC value; the best model was the one with the smallest AIC. Four study sites that did not have geoduck age-composition data (and hence total mortality estimates) from two different survey years were excluded. In addition, the number of "without otters" sites that had repeated survey data was minimal. Therefore, in order to increase statistical power, the supplementary "without otters" sites in Barkley Sound were paired to represent three sites with two years of data (e.g., site $a$ (2002) paired with site $d$ (2005); Table 1).

\section{RESULTS}

\section{Geoduck Densities and Age Composition}

Mean geoduck density ranged from 0.17 to $2.22 \mathrm{~m}^{-2}$ in the two areas with otters near Kyuquot and Quatsino Inlet, respectively (Table 1). Mean geoduck density in a site without otters in Yellow Bank (site $a$ ) decreased significantly from 2.15 to $0.81 \mathrm{~m}^{-2}$ from the first survey in 1995 and the second survey in $2006(t=5.7, p<0.05$; Table 1). No statistically significant differences were observed in mean geoduck density between survey years for 9 out of 10 sites with repeated surveys (all $p>0.05$ ), although mean densities tended to decrease between survey years in the otter sites near Kyuquot (sites $a$ and $b$ ), as well as in an otter site in Forward Inlet (site $b$ ). All other sites showed non-significant increases in density (Table 1).

Sampled geoduck ages spanned well over 100 years, ranging from 2 to 152 years (Table 1). The otter sites at Quatsino Inlet appeared anomalous, as they had older me- dian ages and a greater spread than those of all other sites with repeated survey data (Table 1; Fig. 2). The Welch $t$ test provided strong evidence against the null hypothesis of no difference in mean geoduck age between survey years for 3 of the 5 otter sites (all $p<0.05$; Table 1). No evidence was found to reject the null hypothesis of no difference in mean age between survey years for the otter sites in Kyuquot and near Tofino, or the sites without otters in Millar Channel and Yellow Bank (site $b)($ all $p>0.05$; Table 1). Although the sites without otters in Barkley Sound do not have repeated samples for the comparison, the observed median and mean age of geoducks were greater in Barkley Sound than in all other sites (not including Quatsino Inlet) (Table 1; Fig. 2).

\section{Geoduck Total Mortality Rates}

The Chapman-Robson method was nearly unbiased for the observed range of mortality estimates and sample sizes in our study (Table 2). Simulations indicated very similar results although there was small but consistent bias. Geoduck total mortality estimates ranged from $0.0158 \mathrm{yr}^{-1}$ (SE \pm $0.0014 \mathrm{yr}^{-1}$ ), in a site with otters in Quatsino Inlet (site $a$ ) in 1996, to $0.0478 \mathrm{yr}^{-1}\left(\mathrm{SE} \pm 0.0044 \mathrm{yr}^{-1}\right)$ in the otter site near Tofino in 2008. The otter site near Tofino had high estimates of $Z$ in both survey years compared to the other sites with repeated age samples. In addition, the otter site near Kyuquot (site $a$ ) had the greatest increase in total mortality between the first survey in $1998\left(Z=0.0280 \mathrm{yr}^{-1}, \mathrm{SE} \pm 0.0024 \mathrm{yr}^{-1}\right)$ and the second survey in $2003\left(Z=0.0445 \mathrm{yr}^{-1}, \mathrm{SE} \pm 0.0029\right.$ $\left.\mathrm{yr}^{-1}\right)$. Estimated total mortality for the otter site in Forward Inlet (site $a$ ) and the site without otters in Yellow Bank (site $b$ ) both showed a similar magnitude of increase between surveys. Geoduck age-composition in the sea otter sites near Tofino, Kyuquot and Forward Inlet produced higher estimates of mortality because of an apparent scarcity of individuals older than 20 years in the second survey years. The estimates of total mortality for the sites without otters in Barkley Sound and for the sites with otters in Quatsino Inlet were consistently lower (almost all $Z<0.0200 \mathrm{yr}^{-1}$ ) due to a strong presence of older age classes. Although the average $Z$ was only slightly higher for sites with otters $\left(Z=0.0291 \mathrm{yr}^{-1}\right)$ than without $\left(Z=0.0234 \mathrm{yr}^{-1}\right)$, it was distinctly higher for the otter sites after removing Quatsino Inlet from the analysis (average $Z=0.0369 \mathrm{yr}^{-1}$ ).

\section{The Effects of Sea Otters and Fishing}

Geoduck total mortality was best explained by the random effect of the geographic locations of study sites (Table 3). When otters and fishery landings are included in the model, geoduck mortality is best explained by fishery landings. Removing otters from the model resulted in a smaller AIC and a more parsimonious model. Two large observations (outliers) were present in the data that influenced a departure from the assumptions of normality and homogeneity; however, a likelihood-ratio test determined that the model with fishery landings still performed significantly better than the null model with only the intercept and random effect.

\section{DISCUSSION}

Our analysis suggests that fishery removals of geoduck are the most important correlate of geoduck total mortality in fishing areas along the west coast of Vancouver Island. 


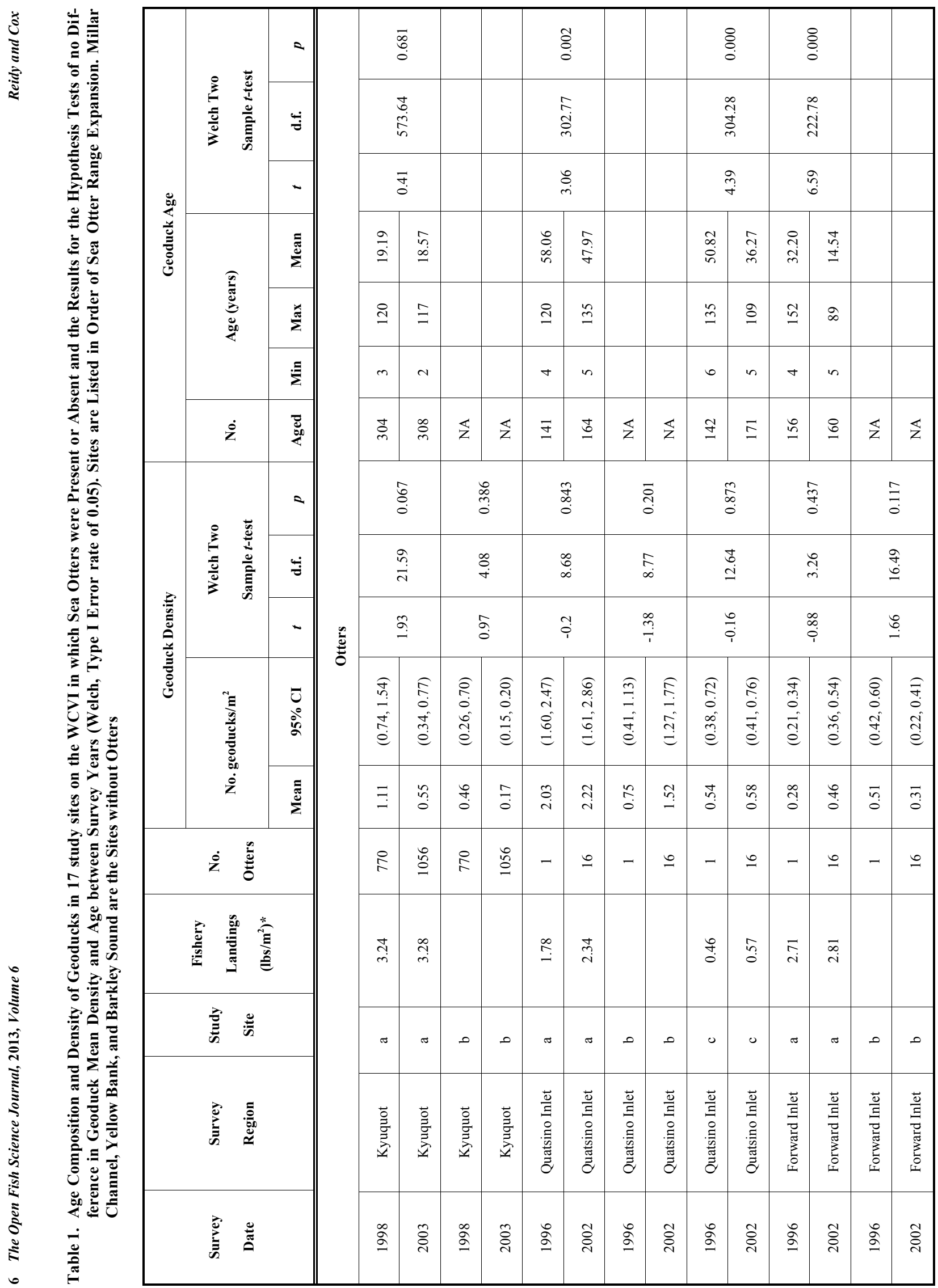




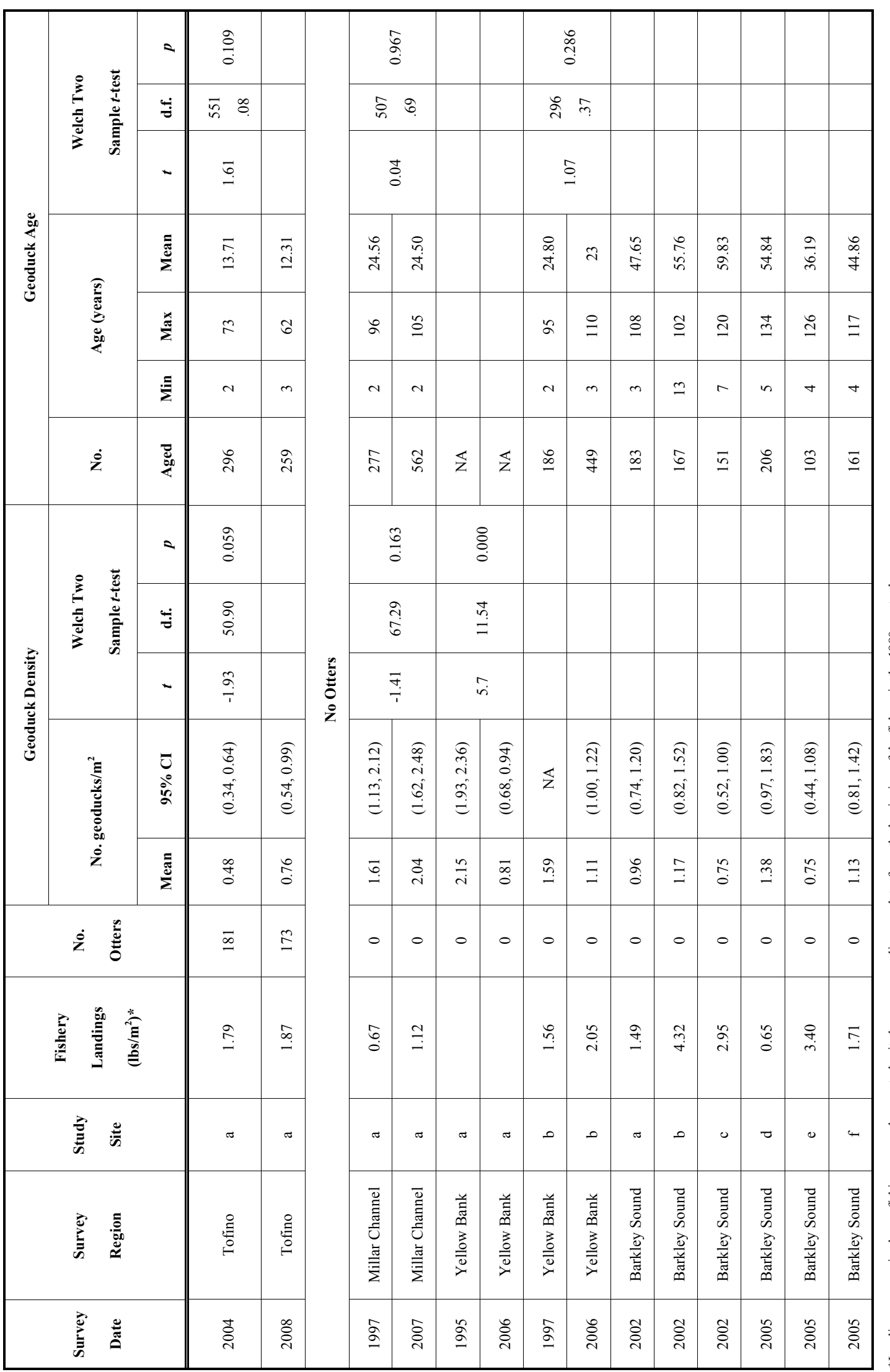




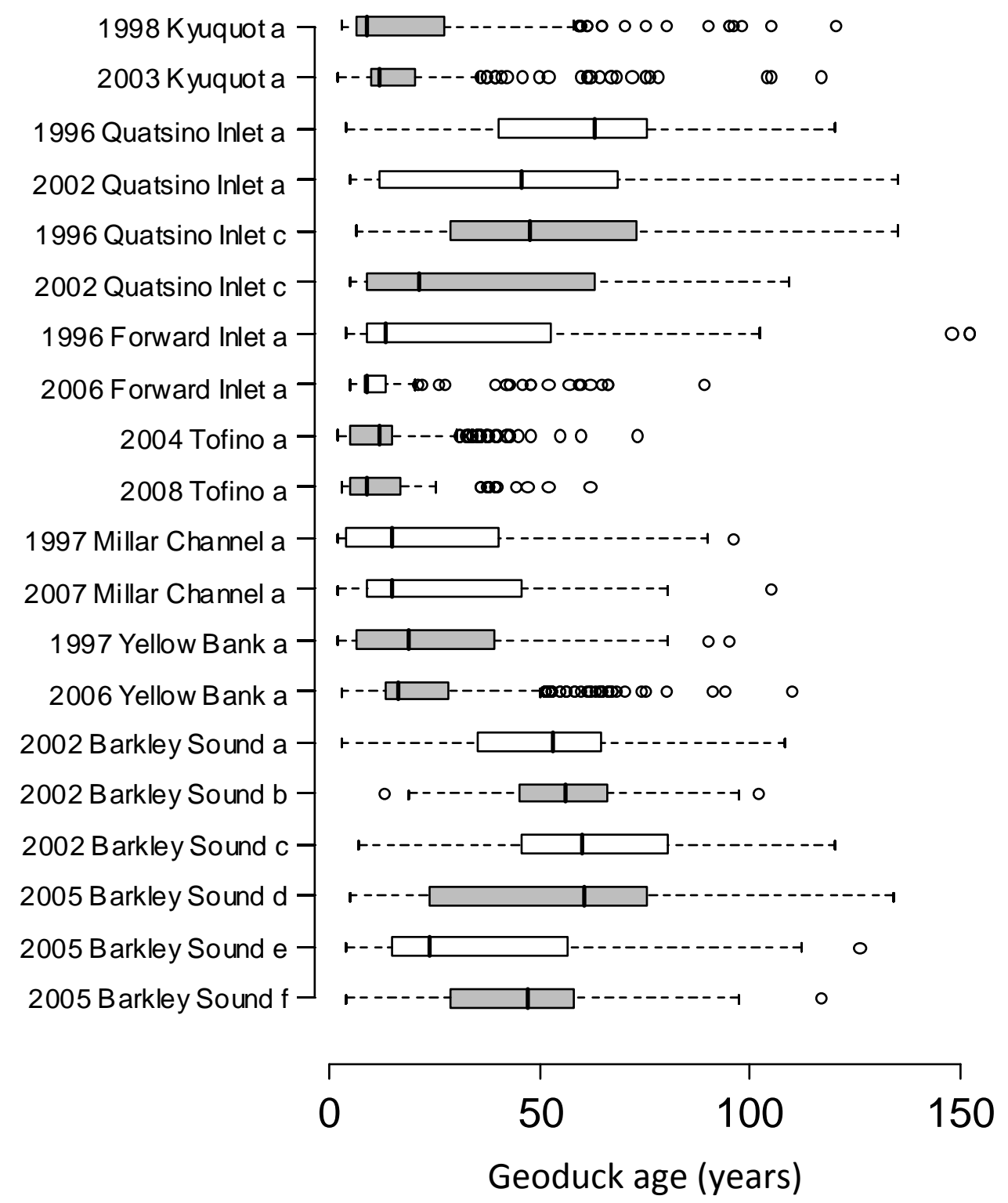

Fig. (2). Age distributions of geoduck samples collected from 7 study sites with repeated age samples and from 6 supplementary sites in Barkley Sound on the WCVI. Alternating colours show matching samples for comparison between survey years, with letters $a-f$ identifying bedspecific geoduck samples collected in two survey years. The bar in the middle of each box shows the median age and is the $50 \%$ quartile. The top of the box, above the median, shows where $75 \%$ of the ages are younger than this value. The bottom of the box, below the median, shows the youngest $25 \%$ of the data. The complete box shows where the middle $50 \%$ of the ages lie (the "interquartile range"), and the whiskers define the minimum and maximum ages. Ages that are 1.5 times greater than the $3^{\text {rd }}$ quartile or less than the $1^{\text {st }}$ quartile are treated as outliers and are plotted as dots. Miller Channel, Yellow Bank and Barkley Sound are the sites without otters. No matching samples were available for the sites in Barkley Sound.

Table 2. Estimated Geoduck Instantaneous Total Mortality $(Z)$ and Associated Standard Error (SE $)_{Z}$ for 13 Study Sites in the WCVI Using the Chapman-Robson Estimator. Simulation Indicated Small but Consistent Bias in the Estimator

\begin{tabular}{|c|c|c|c|c|c|c|}
\hline \multicolumn{4}{|c|}{ Survey } & \multirow{2}{*}{$\begin{array}{c}\text { Number } \\
\text { Geoducks } \\
\text { Aged* }\end{array}$} & \multicolumn{2}{|c|}{ Chapman - Robson Estimator } \\
\hline Date & Location & Study Site & Site Type & & $\mathbf{Z}$ & $\mathbf{S E}_{\mathbf{Z}}$ \\
\hline 1998 & Kyuquot & a & Otter & 137 & 0.0280 & 0.0024 \\
\hline 2003 & Kyuquot & a & Otter & 229 & 0.0445 & 0.0029 \\
\hline 1996 & Quatsino Inlet & $\mathrm{a}$ & Otter & 130 & 0.0158 & 0.0014 \\
\hline
\end{tabular}


Table 2. contd....

\begin{tabular}{|c|c|c|c|c|c|c|}
\hline \multicolumn{4}{|c|}{ Survey } & \multirow{2}{*}{$\begin{array}{l}\text { Number } \\
\text { Geoducks } \\
\text { Aged* }\end{array}$} & \multicolumn{2}{|c|}{ Chapman - Robson Estimator } \\
\hline Date & Location & Study Site & Site Type & & $\mathbf{Z}$ & $\mathbf{S E}_{\mathbf{Z}}$ \\
\hline 2002 & Quatsino Inlet & a & Otter & 129 & 0.0168 & 0.0015 \\
\hline 1996 & Quatsino Inlet & $\mathrm{c}$ & Otter & 135 & 0.0185 & 0.0016 \\
\hline 2002 & Quatsino Inlet & $\mathrm{c}$ & Otter & 105 & 0.0182 & 0.0018 \\
\hline 1996 & Forward Inlet & a & Otter & 84 & 0.0185 & 0.0020 \\
\hline 2002 & Forward Inlet & a & Otter & 52 & 0.0349 & 0.0048 \\
\hline 2004 & Tofino & $\mathrm{a}$ & Otter & 162 & 0.0477 & 0.0037 \\
\hline 2008 & Tofino & $\mathrm{a}$ & Otter & 118 & 0.0478 & 0.0044 \\
\hline 1997 & Millar Channel & a & No Otter & 152 & 0.0240 & 0.0019 \\
\hline 2007 & Millar Channel & a & No Otter & 409 & 0.0312 & 0.0015 \\
\hline 1997 & Yellow Bank & $\mathrm{b}$ & No Otter & 387 & 0.0258 & 0.0025 \\
\hline 2006 & Yellow Bank & $\mathrm{b}$ & No Otter & 111 & 0.0381 & 0.0019 \\
\hline 2002 & Barkley Sound & $\mathrm{a}$ & No Otter & 161 & 0.0186 & 0.0015 \\
\hline 2002 & Barkley Sound & $\mathrm{b}$ & No Otter & 167 & 0.0177 & 0.0014 \\
\hline 2002 & Barkley Sound & $\mathrm{c}$ & No Otter & 149 & 0.0162 & 0.0013 \\
\hline 2005 & Barkley Sound & d & No Otter & 186 & 0.0165 & 0.0012 \\
\hline 2005 & Barkley Sound & $\mathrm{e}$ & No Otter & 91 & 0.0244 & 0.0026 \\
\hline 2005 & Barkley Sound & $\mathrm{f}$ & No Otter & 155 & 0.0212 & 0.0017 \\
\hline
\end{tabular}

* Number of geoducks $>10$ years old in the sample.

Table 3. Linear Mixed Effects Models and Akaike Information Criterion (AIC) to Determine Whether Sea Otters are an Important Factor Affecting Geoduck Total Mortality Among Study Sites on the WCVI. Included in the Model were the Fixed Effect of Fishery Landings and the Random Effect of Geographic Area within which the Study Sites were Located. Location Denotes the Random Effect in the Model

\begin{tabular}{|c|c|c|c|}
\hline Model ID & Predictors & AIC & Delta AIC \\
\hline \hline 1 & Location & -114.58 & 0.00 \\
\hline 2 & Landings + Location & -102.71 & 11.87 \\
\hline 3 & Otters + Location & -96.19 & 18.39 \\
\hline 4 & Otters + Landings + Location & -84.16 & 30.42 \\
\hline
\end{tabular}

There was no strong evidence that sea otter presence affected geoduck total mortality in these areas. Our estimates of total mortality were similar to the range published for geoduck populations in British Columbia and in Washington State, varying between $0.010 \mathrm{yr}^{-1}$ and $0.040 \mathrm{yr}^{-1}[16,21,38,39]$. Despite the lack of a significant sea otter effect, we cannot rule out Zhang and Hand's [22] concern that estimated total mortality rates were higher where sea otters co-occurred with the fishery, because our estimates of total mortality were noticeably high for two otter sites $\left(Z>0.044 \mathrm{yr}^{-1}\right)$; however, a broader perspective of sites showed that total mortality was similarly high for two sites without otters $\left(Z>0.036 \mathrm{yr}^{-1}\right)$. An issue to consider is that our estimates depend upon stable recruitment and mortality; however, there is evidence that both of these are changing between surveys at the same site. The surveys are close enough in time so that some geoduck cohorts probably contributed twice to the $Z$ estimates generated from the age data. The Chapman-Robson estimates should therefore be treated as indices reflecting the status of the age compositions rather than actual estimates of $Z$ during the transition between surveys.

Our ability to measure an additive sea otter component to geoduck mortality may be weakened by several factors. First, geoduck mortality rates are not directly measurable and must be inferred from rather noisy and biased agecomposition data. Although our simulations showed that estimates of total mortality were unbiased, those simulations 
only tested for sample size effects under the assumption that the survival model was correctly specified. The ChapmanRobson estimator was clearly robust for determining total mortality under these circumstances; however, it is expected to be worse with increasing variation in recruitment and mortality [34]. We assumed that geoduck ages were accurate, vulnerability to fisheries was constant at ages $>10$, and that sampling was unbiased by, for example, survey diver selectivity for geoduck size or age. Although we recognize that none of these assumptions is strictly true, we could not develop more sophisticated age-structured models because age-composition data is not collected for this fishery. Thus, constraints associated with modeling total mortality may limit our ability to detect relatively small components of geoduck total mortality rates.

A second possible reason for the apparent lack of effect of sea otters is that their predation may not be strictly additive to fishing. Otters eating clams that were pulled by divers and discarded on the surface (i.e., high grading) is a concern in the geoduck fishery [16]. Otters may also selectively forage on lower quality geoduck (e.g., old or dying geoduck clams that are easily captured). If sea otter predation on geoduck occurs primarily after fishing has disturbed a bed and exposed geoducks, then some of these geoducks may die of causes other than sea otters if sea otters do not eat them first. Of course, there are variations on this extreme in which exposed juvenile clams survive and re-bury, but may have lower long-term survival expectations. But the point is that total mortality would not change much whether otters were present or absent.

Third, it is possible that sea otter size-selectivity is different from fishery and survey selectivity and, therefore, we did not observe the age-classes impacted by otters. Although sea otters are capable of digging up geoducks on their own, they probably do not routinely dig to the full burrowing depths attained by older geoducks (i.e., a depth refuge of some clams [40]). If the otter burrowing depth is less than the typical depth of age-10+ geoducks, then our reassigning of geoduck ages will eliminate our ability to detect any mortality impact on ages less than $10 \mathrm{yr}$. We did not consider younger ages because the survival model performance would get worse as the effects of recruitment and sampling variability would be more prominent at younger ages.

Finally, one consequence of the rather obvious lack of experimental control and replication in this study is that some sites may not fall clearly into "otters" or "without otters" sites. Recall that our low estimate of total mortality in "otters" sites was strongly dependent upon the estimated low mortality rate in Quatsino Inlet, where otters are known to be present (Table 2). The feeding behaviours of sea otters in the presence of paralytic shellfish poisoning (PSP) suggest a possible mis-classification of "otters" sites in this area. Sea otters in southeast Alaska can detect and avoid toxins such as PSP in their prey and switch to alternate and less toxic prey [41]. The effect of these toxins on sea otters in British Columbia is unknown [23]. Nevertheless, we assumed that sea otters foraged everywhere in Quatsino Sound by 2002, where PSP levels were reportedly above the Alaskan sea otter's toxicity threshold in Quatsino Inlet in 2002. PSP levels were below the toxicity threshold in nearby Forward In- let $^{\text {iv }}$. If sea otters initially foraged on less toxic geoduck in Forward Inlet, or on alternate prey in Quatsino Inlet, then our otter sites at Quatsino Inlet may technically be sites "without otters" despite their observed presence there. Fishing activity was also historically low in the sites at Quatsino Inlet, relative to most other sites, so we cannot separate the possible confounding with lower fishing rates.

The apparent lack of a sea otter predation effect on geoduck mortality rates on the WCVI over the period 19962008 , does not necessarily mean that predation by recovering marine mammals will not be important to the future of geoduck fisheries in British Columbia, or in other regions. One reason may be that sea otters have not yet reached population abundances at which they require high numbers of geoduck prey. While there is no reliable estimate of the total number of otters in British Columbia prior to exploitation, approximately 55,000 sea otter pelts were landed in British Columbia from unknown sources between 1789 and 1809, with at least 6,000 from the WCVI [23]. The current population of sea otters in all of British Columbia is less than 5,000 individuals, with 4,110 otters counted on the WCVI [31]. In Southeast Alaska, where competition for shellfish between humans and sea otters is an increasing management problem, the current sea otter population is over 19,000 animals ${ }^{\mathrm{v}}$. Another reason predation on geoduck may be important in the future is that feeding patterns might change over time as sea otters learn more about how to feed on different components of the geoduck population. For example, matrilineal dietary patterns in sea otters are transmitted to the dependent young and can be influenced by environmental phenomena at the population level [42]. Kvitek and Oliver [7] suggested that sea otters in Alaska had not yet learned to identify the deeply burrowing geoduck as a prey item. The situation might be different for sea otters in British Columbia, especially given anecdotal reports of commercial divers' hand-feeding geoducks to a foraging mother sea otter with pup, while fishing near Kyuquot.

Foraging gray whales may also become a more significant local effect on geoducks in the future as the population expands its feeding range into British Columbia. Small numbers of eastern Pacific gray whales (Eschrichtius robustus) migrate every spring to Clayoquot Sound to feed opportunistically on benthic invertebrates in the soft bottom habitats, at least when planktonic prey are less abundant in the area [43]. As the population of gray whales recovers toward prewhaling levels and the carrying capacity of traditional Arctic feeding areas [44], more whales may explore southern habitats as a result (i.e., the British Columbia coast) [43]. Gray whales are large-bodied predators that require high densities of prey to meet their metabolic requirements and they are well-documented to excavate feeding pits in sandy substrates in central Clayoquot Sound [43]. For instance, during a geoduck survey near Tofino in 2008, divers reported seeing several large gray whale feeding pits in the geoduck bed, in addition to old otter holes. Geoduck buried at shallow depths are also vulnerable to other small benthic predators that are

\footnotetext{
iv Canadian Food Inspection Agency, 400-4321 Still Creek Drive, Burnaby, British Columbia V5C 6S7, Canada, unpublished data, 2010.

${ }^{V}$ V. Gill. Marine Mammals Management, U.S. Fish and Wildlife Service, 1011 East Tudor Road, Anchorage, Alaska 99503, personal communication, 2012.
} 
quick to access buried clams after commercial harvests [45], sea otters and gray whales disturb sediments [40].

In other parts of the world marine mammals are having non-negligible impacts on fisheries via learned behaviour. An increasing trend in some fisheries is depredation, in which marine mammals remove or damage fish caught in fishing gear, which can result in economic losses for fishermen and incidental mortality of some animals [46]. A well-documented interaction is that of pinniped depredation on depressed salmonid (Oncorhynchus spp.) populations along the west coast of North America [47]. Salmon harvesters have long considered Pacific harbor seals (Phoca vitulina) competitors, where seal-caused damage to gear and catch is common [47]. California sea lions (Zalophus californianus) similarly depredate salmonids and other species from commercial and recreational fishing gear [47]. A different form of depredation is occurring in the southern and northern oceans between longline fisheries, sperm whales (Physeter macrocephalus) and killer whales (Orcinus orca) [48-50]. Sperm whales and killer whales remove longline catches of bottom fish from hooks, such as sablefish (Anoplopoma fimbria) and Pacific halibut (Hippoglossus stenolepis) [48, 50]. In the Bering Sea, pods of killer whales have followed vessels from one fishing area to another and depredated the largest fish on the lines [48]. Increasing observations of this behaviour are reported for British Columbia longline fisheries as well [51].

In the British Columbia geoduck fisheries, the majority of fishing now occurs off the remote north coast where harvesters continue to discover new geoduck beds [12], and where sea otters are not yet established. Such a situation presents a unique opportunity to design a research program aimed at disentangling the effects of fishing and predation as both fishery development and re-colonisation by marine mammals proceeds. A before-after-control-impact (BACI) study design, which is commonly used for measuring invasive species effects [52], would provide an adequate basis for separating sources of mortality for geoduck populations. A BACI-P design $[53,54]$, in particular, would be valuable because this design deliberately measures the natural variability in response variables (e.g., total mortality, recruitment) in addition to the main impact effects. A BACI-P design for studying geoduckfishery-predation interactions would involve several repeated measures over time made at geoduck control sites with "no sea otters and no fishing" and impact sites comprising (i) sea otters only, (ii) fishing only, and (iii) sea otters and fishing. In addition to reduce sampling from geoduck cohorts that suffered mortality when sea otters were absent, then either the repeated surveys of the sea otter sites would need to be timed sufficiently after the invasion of sea otters, or a more sophisticated estimation approach for $Z$ is needed that uses a time series of samples simultaneously. Nonetheless, although they did not include effects of fishing, Kvitek et al. [40] used a similar approach to identify differences in infaunal prey abundance and size in just two years at sites in Alaska where sea otters had recently become established. Detecting changes in such measurable features as size and abundance is considerably easier than detecting changes in total mortality, as well as partitioning that mortality among competing sources. The main reason is that geoduck mortality rates are not directly measurable and must therefore be inferred indirectly via models applied to age-composition, abundance, and diet data. Because geoduck populations are likely open to and linked by larval recruitment, changes in the age-composition are driven by recruitment, fishing, and predation mortality processes operating simultaneously. Separating these components has proved extremely challenging in multi-species fisheries models even based on long time-series of data and intensive diet sampling. On the other hand, an ability to directly observe sea otter feeding behaviour and diet in British Columbia may alleviate some of these issues.

\section{CONCLUSION}

Conflicts arising from real or apparent resource competition between fisheries and recovering marine mammals are increasing and will soon become a critical item on the management agenda for some fisheries. A recent high profile example is the conflicting management and conservation objectives between northeast Pacific southern resident killer whales and Chinook salmon (Oncorhynchus tshawytscha) [55]. Our results indicate that intensive geoduck harvesting, rather than sea otter predation, is probably mostly responsible for high geoduck mortality rates where they occur. However, the lack of a detectable additive mortality component associated with sea otter predation probably arises from low statistical power to detect such a small effect size in the presence of recruitment variation, age-composition sampling variability, and confounding of otter and fishing mortality components. Only through deliberate management experiments and intensive sampling will we be able to disentangle fishing and predation effects to the level required for fishery decisions. Without an immediate start to such experiments, our uncertainty about these interactions will likely grow in the future as marine mammals increase in abundance and learn to make a living amidst competition with commercial and recreational harvesters. Such an eroding state of knowledge may lead to costly management decisions for both fisheries and recovering marine mammals.

\section{CONFLICT OF INTEREST}

The authors confirm that this article content has no conflicts of interest.

\section{ACKNOWLEDGEMENTS}

We thank the many people at Fisheries and Oceans Canada who provided key logistical support, particularly Dominique Bureau, Ian Murfitt and Wayne Hajas for their database work. Thanks to Eric Rome and Grant Dovey for providing invaluable assistance throughout the project, and Jane Watson and Linda Nichol who provided important clarifications about sea otters in British Columbia. The comments of anonymous reviewers helped to improve this paper. RDR was supported by a Natural Science and Engineering Research Council of Canada (NSERC) Industrial Postgraduate Scholarship. Thank you to the Underwater Harvesters' Association and Archipelago Marine Research Ltd. for their contribution to the scholarship. Further support was provided to SPC by an NSERC Discovery Grant.

\section{REFERENCES}

[1] Hilborn R, Walters C. Quantitative fisheries stock assessment: choice, dynamics and uncertainty. New York: Chapman and Hall 1992. 
[2] Beverton RJH. Analysis of marine mammal-fisheries interactions. In: Beverton JR, Beddington J, Lavigne D, Eds. Marine mammals and fisheries. London, United Kingdom: George Allen and Unwin, 1985; pp. 3-33.

[3] Hollowed AB, Ianelli JN, Livingston PA. Including predation mortality in stock assessments: a case study for Gulf of Alaska walleye pollock. ICES J Mar Sci 2000; 57: 279-93.

[4] Watson JC, Smith TG. The effect of sea otters on shellfisheries in British Columbia. In: Hand CM, Waddell BJ, Eds. Invertebrate working paper. Can Tech Rep Fish Aquat Sci No. 2089, 1996; pp. 262-303.

[5] Estes JA, Palmisano JF. Sea otters: their role in structuring nearshore communities. Science 1974; 185(4156):1058-60.

[6] Estes JE, Smith NS, Palmisano JF. Sea otter predation and community organization in the western Aleutian Islands, Alaska. Ecology 1978; 59(4): 822-33.

[7] Kvitek RG, Oliver JS. Influence of sea otters on soft-bottom prey communities in southeast Alaska. Mar Ecol Prog Ser 1992; 82: 103-13.

[8] Bodkin JL. Sea otter Enhydra lutris. In: Feldhamer GA, Thompson BC, Chapman JA, Eds. Wild Mammals of North America: Biology, Management, and Conservation. $2^{\text {nd }}$ ed. Baltimore and London: The Johns Hopkins University Press 2003; pp.735-43.

[9] Watson J. The effects of sea otters (Enhydra lutris) on abalone (Haliotis spp.) populations. In: Campbell A, Ed. Workshop on rebuilding abalone populations in British Columbia. Canada: NRC Research Press. 2000; vol. 130, pp. 123-32.

[10] Gerber LR, Wooster WS, DeMaster DP, VanBlaricom GR. Marine mammals: New objectives in U.S. fishery management. Rev Fish Sci 1999; 7(1): 23-38.

[11] Fisheries and Oceans Canada. Pacific Region integrated fisheries management plan, green sea urchin: September 1, 2010 to August 31, 2013. Available from: http://www.dfo-mpo.gc.ca/Library/342191

[12] Fisheries and Oceans Canada. Pacific Region integrated fisheries management plan, geoduck and horse clam: January 1 to December 31, 2010. Available from: http://www.dfo-mpo.gc.ca/Library/338994.pdf

[13] Harbo RM. Whelks to whales: coastal marine life of the Pacific Northwest. Canada: Harbour Publishing, Madeira Park, B.C. 1999.

[14] Bureau D, Hajas W, Surry NW, Hand CM, Dovey G, Campbell A. Age, size structure and growth parameters of geoducks (Panopea abrupta, Conrad 1849) for 34 locations in British Columbia sampled between 1993 and 2000. Can Tech Rep Fish Aquat Sci 2002; 2413: 84 .

[15] Campbell A, Harbo RM, Hand CM. Harvesting and distribution of Pacific geoduck clams, Panopea abrupta, in British Columbia. In: Jamieson GS, Campbell A, Eds. Proceedings of the North Pacific Symposium on invertebrate stock assessment and management. Can Spec Publ Fish Aquat Sci No.125. Ottawa National Research Council of Canada Research Press 1998; pp.349-58.

[16] Orensanz JM, Hand CM, Parma AM, Valero J, Hilborn R. Precaution in the harvest of Methuselah's clams the difficulty of getting timely feedback from slow-paced dynamics. Can J Fish Aquat Sci 2004; 61:1355-72.

[17] Fisheries and Oceans Canada. Geoduck Clam. DFO Science Stock. Status Report no. C6-05. Canada: Fisheries \& Ocean Canals 2000.

[18] Zhang Z, Hand C. Recruitment patterns and precautionary exploitation rates for geoduck (Panopea abrupta) populations in British Columbia. J Shellfish Res 2006; 25(2): 445-53.

[19] Hand CM, Bureau D. Quota options for the geoduck clam (Panopea abrupta) fishery in B.C. for 2001 and 2002. PSARC Working paper 2000; pp. I2000-6.

[20] Goodwin CL, Pease B. Species profiles: Life histories and environmental requirements of coastal fishes and invertebrates (Pacific Northwest) - Pacific geoduck clam. US Fish Wildl Serv Biol Rep TR EL-82-4. USA: US Army Corps of Engineers1989.

[21] Zhang Z, Campbell A. Natural mortality and recruitment rates of the Pacific geoduck clam, Panopea abrupta, in experimental plots. J Shellfish Res 2004; 23: 675-82.

[22] Zhang Z, Hand C. Determination of geoduck harvest rates using age-structured projection modelling. Canada: Canadian Science Advisory Secretariat. 2007.

[23] Committee on the Status of Endangered Wildlife in Canada. COSEWIC assessment and update status report on the sea otter Enhy- dra lutris in Canada. Committee on the Status of Endangered Wildlife in Canada, Ottawa 2007.

[24] Ralls K, Eagle TC, Siniff DB. Movement and spatial use patterns of California sea otters. Can J Zool 1996; 74: 1841-9.

[25] Gregr EJ, Nichol LM, Watson JC, Ford JKB, Ellis GM. Estimating carrying capacity for sea otters in British Columbia. J Wildl Manage 2008; 72(2): 382-8.

[26] Species at Risk Public Registry [webpage on the internet; cited April 2, 2011]. Available from: http://www.sararegistry.gc.ca/species/speciesDetails_e.cfm?sid=149

[27] Ministry of Natural Resource Operations: Wildlife in B.C. [webpage on the internet; cited February 12, 2011]. Available from: http://env.gov.B.C..ca/fw/wildlife/

[28] Wendell FE, Hardy RA, Ames JA, Burge RT. Temporal and spatial patterns in sea otter (Enhdrya lutris) range expansion and the loss of the pismo clam fisheries. Calif Fish Game 1986; 72: 197-212.

[29] Kvitek RG, Fukayama AK, Anderson BS, Grimm BK. Sea otter foraging on deep-burrowing bivalves in a California coastal lagoon. Mar Biol 1988; 98: 157-67.

[30] Thomson RE. Oceanography of the British Columbia Coast. Canada: Can Spec Publ Fish Aquat Sci 1991; p. 56

[31] Nichol LM, Boogaards MD, Abernethy R. Recent trends in the abundance and distribution of sea otters (Enhydra lutris) in British Columbia. Fisheries and Oceans. Report No.0.16. Canada: Canadian Science Advisory Secretariat Research 2009.

[32] Stewart-Oaten A, Bence JR, Osenberg CW. Assessing effects of unreplicated perturbations: No Simple solutions. Ecology 1992; 73(4): 1396-404

[33] Chapman DG, Robson DS. The analysis of a catch curve. Biometrics 1960; 16: 354-68.

[34] Dunn A, Francis RICC, Doonan IJ. Comparison of the ChapmanRobson and regression estimators of $Z$ from catch-curve data when non-sampling stochastic error is present. Fish Res 2002; 59: 14959.

[35] Seber GAF. The estimation of animal abundance and related parameters. $2^{\text {nd }}$ ed. London: Arnold 1982.

[36] Fitzmaurice G, Davidian M, Verbeke G, Molenberghs G. Longitudinal data analysis: A handbook of modern statistical methods Boca Raton, Florida: Chapman and Hall/CRC 2009.

[37] Burnham KP, Anderson DR. Data-based selection of an appropriate biological model: the key to modern data analysis. In: McCullough DR, Barrett RH, Eds. Wildlife 2001: populations. London: Elsevier 1992.

[38] Bradbury A, Tagart JV. Modeling geoduck, Panopea abrupt (Conrad, 1849), population dynamics. II.Natural mortality and equilibrium yield. J Shellfish Res 2000; 19(1): 63-70.

[39] Breen PA, Shields TL. Age and size structure in five populations of geoduck clams (Panope generosa) in British Columbia Rep. No.1169 . Canada: Can Tech Rep Fish Aquat Sci No. 1169. 1983.

[40] Kvitek RG, Oliver JS, DeGange AR, Anderson BS. Changes in Alaskan soft-bottom prey communities along a gradient in sea otter predation. Ecology 1992; 73(2): 413-28.

[41] Kvitek R, Bretz C. Harmful algal bloom toxins protect bivalve populations from sea otter predation. Mar Ecol Prog Ser 2004; 271 : 233-43.

[42] Estes JA, Riedman ML, Staedler MM, Tinker MT, Lyon BE. Individual variation in prey selection by sea otters: patterns, causes and implications. J Anim Ecol 2003; 72(1): 144-55.

[43] Dunham JS, Duffus DA. Foraging patterns of gray whales in central Clayoquot Sound, British Columbia, Canada. Mar Ecol Prog Ser 2001; 223: 299-310.

[44] Rugh DJ, Muto MM, Moore SE, DeMaster DP. Status review of the eastern North Pacific stock of gray whales. US Dept Commer NMFS-AFSC-103. NOAA Tech Memo 1999.

[45] Willner G. The potential impacts of the commercial geoduck (Panopea generosa) hydraulic harvest method on organisms in the sediment and at the water-sediment interface in Puget Sound. Master's thesis. Olympia,Washington: The Evergreen State College 2006.

[46] Read AJ. The Looming crisis: Interactions between marine mammals and fisheries. J Mammal 2008; 89(3): 541-8.

[47] Scordino J. West coast pinniped program investigations on California sea lion and Pacific harbor seal impacts on salmonids and other fishery resources. Report for Pacific States Marine Fisheries Commission.US: Pacific States Marine Fisheries Commission 2010. 
[48] Yano K, Dahlheim ME. Killer whale, Orcinus orca, depredation on longline catches of bottomfish in the southeastern Bering Sea and adjacent waters. Fish Bull 1995; 93: 355-72.

[49] Purves MG, Agnew DJ, Balguerias E, Moreno CA, Watkins B. Killer whale (Orcinus orca) and sperm whale (Physeter macrocephalus) interactions with longline vessels in the Patagonian toothfish fishery at South Georgia, South Atlantic. CCAMLR Sci 2004; 11: 111-26.

[50] Sigler MF, Lunsford CR, Straley JM, Liddle JB. Sperm whale depredation of sablefish longline gear in the northeast Pacific Ocean. Mar Mammal Sci 2008; 24(1): 16-27.

[51] Fisheries and Oceans Canada. Depredation by whales. [webpage on the internet; cited April 2010]. Available from: http://www.pac.dfo- mpo.gc.ca/fm-gp/species- species/mammals-mammiferes/docs/depredation-4-2010-eng.pdf

[52] Parker IM, Simberloff D, Lonsdale WM, et al. Impact: toward a framework for understanding the ecological effects of invaders. Biol Invasions 1999; 1(1): 3-19.

[53] Stewart-Oaten A, Murdoch WW, Parker KR. Environmental impact assessment: "Pseudoreplication" in time? Ecol 1986; 67(4): 929-40.

[54] Stewart-Oaten A, Bence JR. Temporal and spatial variation in environmental impact assessment. Ecol Monogr 2001; 71(2): 30539.

[55] Williams R, Krkosek M, Ashe E, et al. Competing conservation objectives for predators and prey: Estimating killer whale prey requirements for Chinook salmon. PLoS ONE 2011; 6(11): e26738.

Received: December 05, 2012

(C) Reidy and Cox; Licensee Bentham Open.

This is an open access article licensed under the terms of the Creative Commons Attribution Non-Commercial License (http://creativecommons.org/licenses/ by-nc/3.0/) which permits unrestricted, non-commercial use, distribution and reproduction in any medium, provided the work is properly cited. 